\title{
COMO AJUDAR A CRIANÇA COM A ESCRITA E A LEITURA
}

\author{
Geraldina Porto Witter \\ Pontificia Universidade Católica de Campinas \\ Universidade de Mogi das Cruzes
}

As sugestões aqui arroladas decorrem de pesquisas, as quais evidenciam a eficiência das mesmas. Elas servem a pais, professores e profissionais que atuam na área de desenvolvimento e recuperação da linguagem oral, da leitura e da escrita. A proposta é principalmente de promoção do ser humano nestas áreas e em seguida de prevenção de problemas. Todavia podem servir como apoio em programas de remediação.

1. Enquanto a criança é alimentada (desde o recém-nascido) converse pausadamente com ela; à medida que ela cresce, aproveite para ir ensinando o nome dos alimentos, dos objetos usados na ocasião; aos poucos introduza informações sobre como são feitos os alimentos, de onde eles surgem, até sobre seu custo.

2. Enquanto dá banho na criança (desde o recém-nascido) converse pausadamente com ela; ao tocar cada parte do corpo dela diga o nome; quando ela já tiver alguma produção peça que repita; que diga o nome (quando já souber) para manutenção ou retenção do aprendido; use jogos: "Agora vou pegar ou lar o..." (dar pistas apontando ou olhando em direção e esperar que ela diga o nome; se não souber, diga-o, se errar, diga "é...".

3. Enquanto veste a criança dizer o nome (e, mais tarde, as cores) das peças de roupa; quando já souber falar, pedir que repita, fazer jogos de adivinhação (o que é que se põe no pé? Depois da ca1cinha a gente põe...; De que cor é a blusa que tenho na mão?).

4. Quando sair com a criança (a pé ou de carro, especialmente a ida-volta à escola já foram bem pesquisadas) é preciso aproveitar para falar com ela, mostrar coisas, ensinar-lhe os nomes das coisas, pedir que diga os nomes. Se estiver no carro (ou ônibus escolar) fazer o mesmo, cantar ou recitar ritmicamente.

\section{Desenvolver conversação}

a) quando no "shopping", supermercado, drogaria etc. conversar com a criança sobre o que está comprando, porque está comprando, quando irá usar, quanto custa; veja o que ela gostaria de comprar (dê algum dinheiro para ela fazer suas próprias compras - 5 a 6 anos é uma idade em que ela já pode fazer isto.

b) quando estiver cozinhando, converse com a criança sobre o que está fazendo, a ordem em que faz, sobre o que ela gosta de comer, como é feito seu prato predileto (fale e mostre como se faz, tantas vezes quantas forem necessárias).

c) antes de sair para um passeio ou excursão (a pé ou de condução), converse com a criança sobre onde vão, o que irão fazer, o que irão ver; quando chegar ao local recorde com ela, diga o nome e o que mais a interessar sobre o que estão vendo ou fazendo; faça jogos verbais e outros durante o passeio (lá vem um barquinho carregadinho de...; o primeiro carro que vem é...).

d) estabeleça um horário para contar história para e com a criança (na escola pode ser logo após o recreio, como período de acomodação; no lar o horário que for mais conveniente, para muitos é na hora de dormir). $\mathrm{O}$ adulto ou a criança começa, outro continua (duas a três orações cada), 
alternando um com outro até acabar a história (invente histórias, mas elas devem ter sempre começo, desenvolvimento e fim).

e) estabeleça uma dia por semana para jogos (em casa e na escola) de memória, de adivinhação, de alfabeto, de números.

6. Ler para a criança - É necessário ler diariamente para a criança, aumentando gradualmente o tempo de leitura de alguns minutos para o recém-nascido, até 20 minutos para a criança de 4 a 5 anos, até meia hora para as mais velhas (excepcionais ou não) que ainda não tenham o domínio da leitura. Pode estabelecer um horário (na escola pode alternar um dia lê, outro conta história, após o recreio, este horário não é o da "aula" de leitura) que julgar conveniente (após o lanche ou antes da hora de dormir) ou simplesmente no momento em que parecer mais conveniente. $\mathrm{O}$ importante é ler, ler, ler muito para a criança, mas sem pressioná-la. Quando na sala de espera de médicos ou dentistas tenha à mão um livro para ler para a criança. O mesmo é válido para viagens longas em qualquer meio de transporte.

São meios para tornar a leitura agradável e educativa:

(a) conhecer a amplitude de atenção da criança e não ir além dela;

(b) conhecer os interesses da criança para escolher material para leitura, com ênfase na discussão do texto e da ilustração (se for ocaso), evitando fazer perguntas de certo ou errado;

(c) fazer questões sobre a história, aceitar os pensamentos e proposições da criança para outras direções na trama da história, evitando perguntas de certo e errado, mas verificar se houve entendimento sobre a mensagem do autor. Ex.: Sobre o que será a história que vou contar? (lê uma parte) Como será que vai acabar?... E agora que vai acontecer? Como gostaria que a história acabasse? e

(d) permita que a criança "leia" com você quando já conhece bem a história.

Quando ler para a criança? Sempre que possível, quanto mais melhor; escolher situações particularmente agradáveis para a criança:

a) ao amamentar, dar a mamadeira ou lanche: recitar poesias infantis, contar ou ler histórias;

b) quando a criança estiver irriquieta, com medo, nervosa, tentar acalmá-la lendo alguma história engraçada ou cantando uma música infantil (ritmos marcados e repetitivos);

c) aproveitar todos os momentos tranqüilos e transformar a própria leitura em um momento tranqüilo;

d) antes de ir ao médico, ao dentista ou de ir tomar vacina, ler para a criança ou com ela histórias que mostrem estes profissionais em ação;

e) ter sempre à mão um livro para ler para a criança em salas de espera (de médicos, rodoviárias, aeroportos, estações de trem; e

f) antes e após ver um programa de TV baseado em um livro, ler e discutir o próprio com a criança ou uma obra similar. Por exemplo, viu um desenho sobre o Patinho Feio, ler o livro com a criança.

7. Permitir que a criança leia - A seqüência começa por aprender a virar a página, "ler" por meio das figuras, "ler" o texto. Elogie cada progresso e atitude, inclusive quando, sem saber ler, a criança "faz de conta" que está lendo. Estimule cada tentativa e interesse pela leitura.

a) Coloque cartazes e livros coloridos (de pano ou cartão) no berço e no cercado do bebê (substituílos semanalmente, usar ciclicamente o que ficou numa semana é guardado por uma semana ou 
duas e depois é recolocado).

b) Organize um espaço para a criança ter sua própria biblioteca (estante de classe).

c) A partir dos 3 anos levar a criança para a hora do conto ou da história na biblioteca pública ou escolar; quando ela já estiver lendo, viabilizar que participe de outras atividades da biblioteca (planejar com o bibliotecário).

d) Faça o registro da criança em alguma biblioteca infanto-juvenil (começar aos 3 anos de idade e encoraje-a a escolher e a retirar livros para ler em casa (planejar com o bibliotecário) só ou com os pais.

e) Recorra a livros que têm fita ou disco gravados para serem usados concomitantemente.

f) Ponha livros em vários lugares em casa para que a criança possa achá-los e lê-los a qualquer momento.

g) Assine revistas infantis para seus filhos ou peça para a bibliotecária tê-los à disposição das crianças.

8. Permitir que a criança escreva - Se a criança vive em uma sociedade que usa a escrita, ela pode começar a aprender a escrever aos 18 meses, ou mesmo antes dependendo da estimulação ambiental e de seu repertório básico. Começa com riscos e formas circulares, abrangendo todo o papel, depois passa a organizá-los no espaço; seguem-se garatujas e riscos já acompanhando o sentido (vertical ou horizontal, esquerda-direita, direita-esquerda) dos modelos de escrita a que foi exposta. A habilidade de escrita requer anos para se desenvolver; é preciso respeitar o ritmo e a produção da criança em cada fase. É preciso valorizar qualquer produção da criança e fornecerlhe oportunidades diárias. Para auxiliar a criança a desenvolver a escrita, é útil recorrer a algumas estratégias:

a) Escrever - seja um exemplo como escritor; escreva, mostre como e quando usa a escrita, escreva para ela, faça listas de coisas que ela goste.

b) Facilidade de materiais - facilite à criança ter acesso a materiais para escrita (papel colorido, lápis, blocos de papel, máquina de escrever, computador, areia, doces etc.).

c) Celebre a autoria da criança - peça que leia o que escreve, fale-lhe sobre a escrita, desenhos, letras, signos; encoraje-a a conversar sobre desenhos e histórias, responda às suas perguntas, seja um bom ouvinte.

d) Valorize a escrita da criança - exponha desenhos e escritos seus na cozinha, no quarto, no quadro de avisos, em varais na classe etc. Organize os melhores em álbuns. Guarde seus primeiros esforços para desenhar ou escrever.

e) Ler para a criança pelo menos 15 minutos por dia ajuda seu desenvolvimento da escrita.

t) Conte histórias clássicas da literatura infantil e outras sobre a vida diária, encorajando-a a recontar, modificar e a desenhar combinando história e texto.

g) Encoraje a criança a incluir a escrita como atividade diária, tanto em casa como na escola.

h) Dê tempo para a criança aprender, apresente modelos corretos, sem destruir ou considerar "erros" respostas que são apenas típicas de uma fase de seu desenvolvimento.

i) Responda a todas as perguntas da criança sobre escrita e leitura; quando não souber, mostre que irá (faça-a ver isto e ajudá-la) procurar nos livros a resposta.

j) Use jogos de letras para a criança brincar (desde os 2 anos), vá ensinando aos poucos os nomes das letras (associar com nomes dela, pais, irmãos, avós, colegas) aos poucos, brincando, vá 
ensinando ajuntá-las, escrever, copiar, ler recados).

k) Ponha em letras de formas maiúsculas em um canto do papel o nome dela (desde a 1 a folha que receber).

I) Quando "desenhar" ou "escrever", pergunte o que é e escreva em letra de forma maiúscula o que ela dizer ao lado do "desenho" ou "escrita".

\section{Lembrar-se sempre de que pais e professores são modelos de leitores e de escritores}

a) Em lugar tranqüilo leia, escreva e cante para e com a criança (desde recém-nascida).

b) Quando passear em parques e jardins, leve material para ler, pintar, e cante com a criança.

c) Quando um brinquedo ou jogo tiver instruções ou regras e a criança não souber ler, leia para ela mostrando onde a matéria está escrita (repita a cada vez que for usar o jogo ou o brinquedo).

d) Estabeleça uma hora da leitura em família (leitura individual ou coletiva), com duração e regras estabelecidas em conjunto, de acordo com as necessidades da família (fazer o mesmo em classe), contar com um período de tempo para comentar as leituras.

e) Comentar com os filhos e alunos o que tiver lido de interessante (jornais, revistas, romances).

f) Explique à criança que precisa de algum tempo de silêncio para que você possa ler, solicitando que faça o mesmo por alguns minutos.

g) Quando não tiver material em casa ou em classe para responder às questões da criança, vá com ela à biblioteca para achar um livro sobre o assunto.

h) Oriente a escolha de livros na biblioteca.

i) Faça visitas orientadas com a criança a livrarias e a exposições de livro.

j) Mantenha-se informado sobre pesquisas que tratam dos temas preferidos e níveis de textos para leitores de várias idades. 